(C) 1995 Kluwer Academic Publishers. Printed in the Netherlands.

\title{
Facilitating small-group learning: a comparison of student and staff tutors' behavior
}

\author{
JOS H. C. MOUST \& HENK G. SCHMIDT* \\ University of Limburg, Maastricht, The Netherlands; *Dr. Moust is assistant professor and \\ Dr. Schmidt is professor, Department of Educational Development and Research. \\ Correspondence and requests for reprints should be addressed to Dr. Moust, Department of \\ Educational Development and Research, University of Limburg, P.O. Box 616,6200 MD \\ Maastricht, The Netherlands.
}

\begin{abstract}
This study focused on students' observations of student and staff tutors' behavior during two academic courses, using a thirtynine-item rating scale. The study took place within an integrated problem-based law curriculum. Six major factors in tutors' behavior were identified. Differences between student and staff tutors' performance were investigated. The results showed that student tutors were better at understanding the nature of the problems students face in attempting to master the subject-matter. Student tutors were also more interested in students' daily lives, study experiences and personalities. In addition, student tutors referred to end-of-course examinations more frequently than staff tutors to direct student learning. Alternatively, staff tutors used their subject-matter expertise more often and displayed more authoritarian behavior than student tutors. No differences were found with respect to tutors' focus on cooperation among group members. The results are interpreted in terms of the nature of the knowledge and experiences of students and staff with regard to problem-based learning and its requirements.
\end{abstract}

Problem-based learning is the main educational approach of the Faculty of Law at the University of Limburg. Problem-based learning can briefly be characterized as follows: A collection of carefully constructed problems is presented to small groups of students. These problems usually consist of a set of observable phenomena or events which are in need of explanation. A representative problem is, for instance, the following:

The revoked residence permit

Vitto Giovanni is an Italian foreign worker, who has lived in Amsterdam for several years. He has a legal residence permit. He is living with Sonja van Holland, whom he wants to marry immediately after his divorce with his legally married spouse in Italy. His future is shattered after he has been caught by the police in flagrante delicto, when he was stealing some goods. The Court sentenced him to eight months' imprisonment and a probationary period of two years. Even worse for him is a message from the Secretary of Justice that he will revoke Vitto's residence permit. This 
would lead to Vitto's expulsion from the Netherlands. When she receives this message Sonja van Holland immediately contacts Vitto's lawyer.

The task of the student group is to discuss these problems and produce tentative explanations for the phenomena described in terms of some underlying processes, principles or rules. Essential to the method is that students' prior knowledge is, in itself, insufficient to understand these problems in depth. During initial discussion dilemmas will arise and questions will be raised that can be used as learning goals for subsequent self-directed learning. After a period of individual study, students return to their group to discuss what they have found in the literature. When some of the information studied is confusing or ambiguous and group members, therefore, do not understand aspects of the literature processed, peers can try to explain to each other what has not been apprehended. In addition, they have to structure the subjectmatter and apply their newly-acquired knowledge to the problem-at-hand to check whether they are now better able to understand it - and possibly solve it (Schmidt 1983). As novices in a domain, students, however, can easily misinterpret parts of the relevant subject-matter or remain superficial in their discussions using terms and concepts without real, deep comprehension. In order to guard against superficiality and the emergence of misconceptions, a tutorial group is guided by a tutor, usually a faculty member. The primary task of a tutor is to facilitate students' learning processes, i.e. helping the students to integrate and use information, and, secondly, to help students to interact effectively in the small-group tutorial. The tutor can do so by asking probing questions to challenge students' points of view and by providing (counter) examples and metaphors which help students to remember the subject-matter better. He or she can contribute - if necessary - with some subject-matter information, evaluate progress being made and monitor the extent to which each group member contributes to the group's goals. Moreover, the tutor can provide the group with feed-back about the way members communicate with one another, encourage less talkative members, help the student who chairs the meeting, and foster group development. Central to the task of a tutor is the facilitation of the students' learning rather than direct teaching. Tutor interventions must encourage students' autonomy (Barrows 1988; Schmidt 1983). From this brief discussion, it may be clear that the tutor plays an important role in encouraging and guiding students in their learning. This is not an easy task, because the range of a tutor's possible actions is to a large extent determined by the situation. What the tutor may contribute depends on the level of self-directedness students have already reached and the kind of difficulties students encounter while working on the problem at hand.

Problem-based learning, however, is a fairly staff-intensive approach to education As a solution to this problem, schools sometimes hire advanced 
undergraduate students as tutors. Immediately, of course, the question arises whether student-guided groups perform as well as staff-guided groups. Research on the effects of peer staff versus tutoring on student achievement is generally inconclusive. de Volder, de Grave \& Gijselaers (1985); de Grave, de Volder, Gijselaers \& Damoiseaux (1990); Gruppen, Traber, Paine, Woolliscroft \& Davis (1992) and Moust (1993), for instance, found no differences in achievement. Studies of Moust, de Volder \& Nuy (1989) and Schmidt, Van der Arend, Kokx \& Boon (this issue) revealed, however, staff-guided groups to achieve better.

Moust (1993) discusses a number of possible explanations for this state of affairs. The studies cited, for instance, differed in the magnitude of the samples studied, in the way students' achievement was assessed (Cate 1986), the subject-matter studied by the students involved or the way problem-based learning was implemented.

In this article, we will concentrate on differences in tutor behavior displayed by students and staff tutors as a possible source of differences in performance, or lack thereof. Our point of departure is a study by Moust (1993). In two field experiments, Moust investigated effects of staff versus peer tutoring on student achievement. In the first experiment, 230 first-year law students participated. These subjects were randomly assigned to either a staff or a student tutored group. These groups met twice a week to work on various problems related to lawbreaking behavior. The course under study lasted eight weeks. At the end of the course, Moust found no differences in achievement between his two experimental conditions. This finding was replicated in a second experiment, involving 160 students in an eight-week course on lawmoderated action. Again, no differences in achievement were found. It can be argued that these findings are counterintuitive. Because staff tutors can be expected to have more and more relevant knowledge of the topics at hand, one would expect students guided by such a tutor to benefit from his or her more extended subject-matter knowledge and do better on the end-of-course test. If this is not true, it implies that student tutors must compensate in one way or another to make up for their relative lack of content expertise. The question, therefore, is, in what ways student tutors differ from staff tutors. A first possibility is that the absence of faculty in a small discussion group enables students to communicate more freely with each other about the topics at hand. Some studies have shown that teachers often claim half or more of the time (Bender 1983; Powell 1974; Webb 1983). By consuming so much time, students are able to express their ideas only to a limited extent. However, in discussion groups where students have to teach themselves, because the teacher is either absent or withdraws from the discussion, the members of the groups actually benefit from helping one another. The assumption is that 
this activity expands their knowledge. By doing so information will be more easily remembered (Webb 1989).

A second possibility is that the knowledge structures of the student tutor resemble the knowledge structures of the students to a larger extent than those of staff tutors. In a review on the role of students as teachers, Cornwall (1980) suggests that staff differ from students with respect to their knowledge of the subject-matter in a fundamental way. Faculty possess more elaborated, more accurate and more differentiated knowledge structures. The cognitive schemas of advanced undergraduate students, however, can be expected to be more similar to first-year students in terms of complexity and extent of integration. Cornwall coins the term 'cognitive congruence' to denote this resemblance of cognitions between students and their student tutors. So, Cornwall assumes that the peer tutor is better able to help students to master subject matter because

... his explanation is almost bound to be at the same conceptual level as that of his peers; he will be very likely only to refer to linking concepts, relationships and facts that are part of the learner's knowledge; he will use language at the same level as his peers. The teacher-expert on the other hand must always try to empathize with the learner. ... Even the best teacher is not always very successful in this respect (p. 84).

A third hypothesis is based on the idea that students benefit more from learning guided by peer tutors, because peer tutors interact in a more directly and personally way with the students. So, a safer and more open learning environment is created (Collier 1983; 1985; Sarbin 1976).

Research into differences in student and staff tutors' performance in smallgroup tutorials is scant. De Grave, de Volder, Gijselaers \& Damoiseaux (1990) asked students to fill in a rating scale about their tutor's behavior. Discriminant analysis was performed indicating that student-tutors' performance differed significantly from staff-tutors' performance. De Grave et al. found that staff tutors more often seemed to have a clear notion of the objectives of the course, volunteered more often to explain things and supervised more closely the interaction process in the group. Student tutors, on the other hand, seemed more often to arouse interest in the subject-matter among their students and evaluated more regularly the group's proceeding. Schmidt, Van der Arend, Kokx \& Boon (1993a) compared 118 staff- and 168 student-tutors' performance in 4 curriculum years of a faculty of health sciences. These tutors ran in total 583 small-group tutorials. Schmidt et al. showed that staff tutors made more 'extensive use of their subject-matter knowledge' than peer tutors. However, a significant interaction effect indicated that peer tutors used their knowledge more in the first year, whereas staff tutors were judged as more 
active in this respect in the three subsequent years. The same phenomenon was found with respect to the 'the relevance of the tutor's contribution' and 'asking stimulating questions'. Peer tutors were rated higher on these behaviors in the first year, whereas staff were rated higher in subsequent years. A different pattern, however, emerged with respect to 'evaluating the group's functioning'. Student tutors evaluated more extensively than staff tutors in all curriculum years. (A study into differences between content-expert tutors and non-expert tutors by Schmidt, Van der Arend, Mous?, Kokx \& Boon (1993b) produced the same pattern).

In summary, these studies suggest that staff tutors use their expertise more often to help students to get a grip on the subject-matter, while student tutors appear to give more attention to general process facilitation.

In the study to be presented here, this distinction between 'processfacilitation' and 'subject-matter-input' behaviors was carried further. Based on the literature reviewed and interviews with students on the performance of staff and student tutors, a rating scale was devised to study the actual behavior of the tutor as observed by the students.

As has been said; two main components of the tutor role were distinguished: the way a tutor handles the knowledge students must acquire, and the way a tutor establishes a personal relationship with the members of the group. Within the subject-matter-input component, three different elements were distinguished. The first was 'use of expertise': To what extent does a tutor use his or her subject-matter expertise to help students? The second was 'cognitive congruency': To what extent is a tutor able to understand, and to express him or herself at the students' level of knowledge? The third was denoted as 'assessment orientation': To what extent does a tutor stress the importance of the end-of-course test to direct the students' learning? The other main component distinguished, the process-facilitation component, also included three elements. The first was, 'authority': To what extent does a tutor exercise his or her power to direct students' activities in the group? The second 'role congruency': To what extent is a tutor able to empathize with and relate to students' life experience? And the third was 'focus on cooperation': To what extent is a tutor interested in the cooperation process in the group? It was hypothesized that staff tutors would use their expertise and authority more frequently than student tutors. On the other hand, it was expected that student tutors would be better able to estimate their students' knowledge level and discuss subject-matter at that level. In addition, it was expected that student tutors could empathize with their students' life experiences. It was also thought that student tutors would be more assessment-oriented and would be more focused on the cooperation in the group. To that end, a rating scale consisting of six subscales was developed and validated. These subscales 
were then used to study possible differences in behavior patterns between student and staff tutors.

\section{Method}

\section{Subjects}

Subjects were all students attending small-group tutorials guided by student tutors or staff tutors in two successive courses of the first year curriculum. Each course lasted for eight weeks. In the first course 202 students participated, guided by seven staff and six student tutors. Each tutor monitored two small-group tutorials. In the second course, 150 freshman engaged in 18 groups guided by four staff and five student tutors. Students met in their groups twice a week for two hours. Student tutors were recruited by an open selection procedure. Third-and fourth-year undergraduate students were selected to fulfil the role of tutor during the first curriculum year. Student tutors received the same preparation for the tutor role as staff before contributing to the curriculum. After the course a student from every small tutorial group was interviewed to extract a more elaborated opinion about student and staff tutors' performance.

\section{Instrument}

For all behavioral components appropriate items were developed. Tutors' performance was measured by means of a 39-item Likert-type rating scale. Nineteen items consisted of a statement with which students could indicate the intensity of tutors' behavior. Students had to mark on a five-point scale whether the tutor performed the behavior 'to a very limited extent' (1), 'to a limited extent' (2), 'sometimes' (3), 'to a great extent' (4) 'to a very great extent' (5). Twenty items asked for the frequency of tutors' behavior. Students had to fill in whether their tutor performed the behavior never (1), sometimes (2), regularly (3), often (4) or always (5). Several items from every category are displayed in Table 1.

The rating scale was part of a larger rating sale which asked students to give their opinion about the quality of all aspects of the educational facets of the course, e.g. the quality of the learning materials offered, the quality of the lectures and practicals. 
Table 1. Example of categories of tutor performance and items describing tutor behavior.

\section{Use of expertise}

- The tutor used his or her subject-matter knowledge to help us.

- The tutor emphasized applying our knowledge to practical examples.

- The tutor corrected us by appealing to his or her subject-matter expertise.

- The tutor did contribute using his or her subject-matter knowledge.

\section{Cognitive congruence}

- The tutor was able to understand problems we had with the materials.

- The tutor asked questions we could understand.

- The tutor used the same terminology as we did.

- The tutor succeeded in explaining topics comprehensibly.

\section{Test orientation}

- The tutor wamed us that this unit was not easy.

- The tutor mentioned subjects we certainly had to know for the assessment of this unit.

- The tutor referred to the success and failure rates of this unit in last academic year.

\section{Authority}

- Tutor's performance hampered me from showing that I did not understand a subject.

- The tutor belittled us when we discussed a topic in a wrong way.

- The tutor behaved pedantically or schoolmasterish.

- The tutor checked whether we had done our homework.

\section{Role congruence}

- The tutor appreciated our efforts.

- The tutor was involved with our study.

- The tutor understood the problems freshmen have with their study.

- The tutor was interested in subjects related to our personal conditions of living.

\section{Cooperation orientation}

- The tutor was interested in the performance of the tutorial group.

- The tutor was interested in the discussion leader's performance.

- The tutor evaluated the group's functioning with us.

\section{Reliability and validity of the instrument}

To assess the reliability of the subscales, a generalizability study was conducted (Cronbach, Gleser, Nanda \& Rajaratnam 1972). Table 2 shows the generalizability coefficients of all dimensions when the rating scale was filled out by 5,8 or 11 students. 
Table 2. Coefficients of generalizability with 5,8 and 11 students in course 1 and course 2.

\begin{tabular}{|c|c|c|c|c|c|c|}
\hline \multirow{3}{*}{ Scale } & \multicolumn{3}{|c|}{ Course 1} & \multicolumn{3}{|c|}{ Course 2} \\
\hline & \multicolumn{3}{|c|}{ Number of students } & \multicolumn{3}{|c|}{ Number of students } \\
\hline & 5 & 8 & 11 & 5 & 8 & 11 \\
\hline Use of expertise & 0.91 & 0.93 & 0.94 & 0.86 & 0.88 & 0.89 \\
\hline Cognitive congruence & 0.77 & 0.83 & 0.86 & 0.74 & 0.81 & 0.84 \\
\hline Test orientation & 0.61 & 0.72 & 0.78 & 0.40 & 0.52 & 0.60 \\
\hline Authority & 0.68 & 0.73 & 0.76 & 0.71 & 0.76 & 0.79 \\
\hline Role congruence & 0.72 & 0.80 & 0.85 & 0.79 & 0.83 & 0.86 \\
\hline Cooperation orientation & 0.50 & 0.61 & 0.69 & 0.77 & 0.84 & 0.87 \\
\hline
\end{tabular}

As Table 2 indicates, the reliability is satisfactory when the judgement of 11 students (the normal number of students in a tutorial group) is used.

To assess the construct validity of the instrument the confirmatory factor analysis approach was used. By means of the programme EQS (Bentler $1985)$ the structure of the dimensions was tested. The results of this analysis was chi square $=1004.20$, df $449, p<0.001$. The Bentler-Bonnett normed fit index was 0.66 , the Bentler-Bonnett nonnormed fit index was 0.75 and the comparative fix index was 0.78 . These findings suggest that the model including six subscales do not entirely fit the data. A reason may be that the subscales are correlated, which is not surprising. For theoretical reasons it was decided to use the six components as the basis for a comparison, despite mixed empirical support.

\section{Procedure}

Students filled out the rating scale at the end of both courses in an educational setting in which their tutors were absent. At the end of both units in the first year curriculum all students answered the rating scale. For each unit, students and tutors were randomly assigned to the tutorial groups. The rating scale was administered to all students during a regular end-of-term programme evaluation session. The data were analyzed using one-way analysis of variance (ANOVA). 
Table 3. Means, standard deviations and levels of significance in the first course.

\begin{tabular}{llrlllll}
\hline Dimension & $\begin{array}{l}\text { Group guided } \\
\text { by }\end{array}$ & $\mathrm{N}$ & $\mathrm{X}$ & $\mathrm{Sd}$ & F-obs. & p-obs. \\
\hline Use of expertise & student tutors & 96 & 3.1 & 0.4 & 1.41 & n.s. \\
& staff tutors & 106 & 3.1 & 0.5 & & \\
& & & & & & \\
Cognitive congruence & student tutors & 96 & 3.7 & 0.4 & 17.00 & 0.001 \\
& staff tutors & 106 & 3.4 & 0.6 & & \\
Achievement orientation & student tutors & 96 & 2.5 & 0.5 & 8.06 & 0.005 \\
& staff tutors & 106 & 2.3 & 0.8 & & \\
Authority & & & & & & \\
& student tutors & 96 & 1.7 & 0.6 & 4.05 & 0.05 \\
& staff tutors & 106 & 1.8 & 0.7 & & \\
Role congruence & student tutors & 96 & 3.0 & 0.6 & 23.34 & 0.001 \\
& staff tutors & 106 & 2.6 & 0.6 & & \\
Cooperation orientation & student tutors & 96 & 2.9 & 0.7 & 0.47 & n.s. \\
& staff tutors & 106 & 2.9 & 0.7 & & \\
\hline
\end{tabular}

\section{Results}

Tables 3 and 4 show differences between student tutor performance and staff tutor performance in both successive courses. The outcomes generally confirmed the hypotheses. Staff tutors used their expertise more often than student tutors. Although this outcome was found in both courses, only the results in the second course showed significant differences. Further, differences were found, in both units, with respect to tutors' authority. Staff tutors exhibited more authoritarian behavior than student tutors. In the interviews students commented on staff and student tutors' authority to in the following way:

'immediately the tutor kept aloof from us: "I will tell you nothing, you are responsible for yourself and you have to do it yourself. If something screws up I will tell you." He showed this attitude from the first moment. When this happened you got a feeling like "I will stay at a distance as well".'

'You are students together. Very often you look up to a member of the faculty staff. That is wrong of course, but you have to overcome a threshold. If you are guided by a student tutor, you can talk with them more freely.' 
Table 4. Means, standard deviations and levels of significance in the second course.

\begin{tabular}{lllllll}
\hline Dimension & $\begin{array}{l}\text { Group guided } \\
\text { by }\end{array}$ & $\mathrm{N}$ & $\mathrm{X}$ & $\mathrm{Sd}$ & F-obs. & p-obs. \\
\hline Use of expertise & student tutors & 87 & 3.0 & 0.4 & 9.85 & 0.002 \\
& staff tutors & 63 & 3.2 & 0.5 & & \\
& & & & & & \\
Cognitive congruence & student tutors & 87 & 3.6 & 0.5 & 16.03 & 0.001 \\
& staff tutors & 63 & 3.3 & 0.6 & & \\
Achievement orientation & student tutors & 87 & 2.4 & 0.6 & 10.41 & 0.002 \\
& staff tutors & 63 & 2.1 & 0.6 & & \\
Authority & & & & & & \\
& student tutors & 87 & 1.5 & 0.4 & 30.62 & 0.001 \\
& staff tutors & 63 & 2.0 & 0.7 & & \\
Role congruence & & & & & & \\
& student tutors & 87 & 3.1 & 0.6 & 40.67 & 0.001 \\
& staff tutors & 63 & 2.5 & 0.6 & & \\
Cooperation orientation & student tutors & 87 & 2.8 & 0.7 & 2.91 & n.s. \\
& staff tutors & 63 & 2.6 & 0.8 & & \\
\hline
\end{tabular}

The outcomes concerning cognitive congruency were also in line with the assumptions. Student tutors were better at understanding the nature of the problems students faced in attempting to master the subject-matter in both courses. All differences were significant and relatively large. In the interviews students commented on student tutors' empathy to understand their difficulties with the learning materials in the following way:

'Well, I prefer a student tutor. Because they are much closer to the mind of the student. They see through our difficulties because they have already encountered them themselves. They are more involved with the subjectmatter. I think they see very clearly which difficulties you can have with certain aspects of a subject. Whether you are not able to discern the main directions or whether you do not understand the details.'

'She (a student tutor) understood exactly the problems we were struggling with at certain moments. Other tutors said after a while "Oh, now I understand what your problem is, well, that can be explained so and so" but she was mostly able to say in one word what our difficulties were.' 
The outcomes concerning role congruency were also in line with the assumptions. Student tutors were more interested in students' daily lives, study experiences and personalities. All differences were significant and relatively large. Student tutors' ability to empathize with students' personal difficulties was voiced in the following ways:

'Student tutors know what you have to do, how a small tutorial group has to perform. They are educated in problem-based learning. They have grown up with this approach. They know what a student needs from his or her tutor. And ..., I am often disappointed by staff tutors. The staff tutor I had in the last course was not really interested. Whether you were present or not, whether you were engaged or not. (S)he was not engaged. Whereas student tutors show involvement by saying "Come on, you have to be here. These are really important materials. We will master it together. And if you have any trouble, you can come to me." If you are that close, that is much more pleasant. Then you feel much more motivated to get your teeth into the stuff.'

'I really enjoyed it, the way our (student) tutor was guiding the group. She was so motivated. I was curious to know why she was so attentive. Frequently she remarked: "Yeah, as a first year student I had trouble in understanding that literature myself. I got some grip on it by working so and so," or: "You have to be keen on those aspects, they are really important in the next year." She showed us her own route of learning, her own problems with the learning materials and the way she tried to solve them. She also told us a lot about her own experiences with problem-based learning.'

Significant differences were also found with regard to assessment orientation. Student tutors used the end-of-course exam more frequently than staff tutors to direct students' activities in the small-group tutorial. Finally, no differences were found with respect to tutors' focus on cooperation between the members of the group. In the interviews students make the following observations:

'Student tutors also give you information about what you have to study for your exams. "That is a really relevant piece of information, you should know that, you should get a question about it," or: "That piece of information you will need often in the next years." Student tutors have that still fresh in their minds. And because they have that experience themselves, they are better able to transmit it to us. They are better able, in comparison to staff tutors, to give us examples of assessment. They know what is really important for the achievement test.' 
'Sometimes, the student tutor has shown us what we have to know for the end-of-course test. She gave us very important cues, such as "You should write down the different opinions and judgements of those authors, then you get more credit points." And she was right. She gave us good tips on how to answer an end-of-course-test, e.g. she said: "If you write it down in this-and-that way and if you mention those concepts instead of these ones, you will be evaluated more positively. They (the judges) wants us to use those terms, and not only a nice explanation." I think student tutors are more engaged in the achievement tests themselves and that is why they sympathize with us. Because they are studying at the same time as us for their own end-of-course test.'

\section{Discussion}

Previous research has suggested that staff tutors guide small-group tutorials in a way different from student tutors with respect to subject-matter input and process facilitation (De Grave et al. 1990; Schmidt et al. 1993a). The present study sought to extend our understanding of the factors involved. If student tutors do not have as much expertise as staff tutors, are they compensating for this lack of content knowledge by giving, e.g., more attention to the learning difficulties of their small-group tutorial students?

The outcomes of the present study seem to support the assertion that student tutors guide small-group tutorials in a way that is different from staff tutors. With respect to the subject-matter contributions staff tutors seem to use their expertise more frequently and intensively than student tutors. ${ }^{1}$ Student tutors, however, seem to compensate for their lack of expertise by being more cognitively congruent and by devoting more attention to the end-of-course test. These findings leave one with the impression that student tutors do understand the problems first-years have in the comprehension of the subject-matter as well as the demands that an university education requires. Because student tutors seem to be better able 'to speak the language of the students' they appear more competent in offering the members of their small tutorial groups suggestions that the first-years can comprehend.

\footnotetext{
${ }^{1}$ In this study content expertise was considered equivalent to the level of training of the tutor and not so much to his or her specific knowledge. In both the courses researched several non-lawyers in the strict sense of the word were acting as a tutor, e.g. a law sociologist was guiding small-group tutorials. It may be possible that some student tutors show up more content expertise on the subject-matter in the course than these non-lawyers. By removing a number of non-expert staff in his analysis, Moust (1993) demonstrated - a posteriori - that content expertise indeed made a difference in terms of student achievement.
} 
Conversely, staff tutors guide the process of learning and studying from a relatively remote 'cognitive distance.' They seem to be less able to imagine the problems students have with knowledge acquisition. According to students, staff tutors display a tendency to rapidly correct what students contribute to the discussion where a more restrained attitude might be more productive in the longer run.

With respect to the process-facilitation component we also found differences between staff and student tutors. An interesting finding was that staff tutors behave in a somewhat more authoritarian way than student tutors (although differences are smaller than some would expect). Student tutors were not only less authoritarian; they were also more interested in the students' perception of their environment. They tended to be more aware of the problems students encounter by studying in general and by studying in a problem-based learning context more specifically.

Of course there are some factors limiting the validity of our findings. In particular the use of post-hoc administered questionnaires may have influenced the students' judgements with regard to their tutor. It is well-known that subjects overall judgements may suffer from 'halo' effects in which isolated experiences with a judged person may generalize to the overall judgement, skewing it in the direction of the possibly not representative experience. It is, however, unlikely that the meaningful differences found in the judgements of the peer and staff tutors' behavior are the result of these random processes. More problematic may be that students knew whether their tutor was a student or a member of the academic staff. This may have influenced their judgements in more systematic ways. In order to avoid these pitfalls, it is necessary to conduct observational studies measuring tutors' behaviors on-line rather than post-hoc. Such studies may in addition contribute to a more detailed perspective on the role of the tutor in problem-based learning than is possible using questionnaire techniques.

What are the implications of these differences for student learning? Schmidt et al. (1993b) demonstrated significant relationships between tutors' levels of subject-matter input and average achievement scores as well as tutors' level of skill in process facilitation and average achievement scores. In a more detailed analysis, Moust (1993) showed a complex causal relationship between the various tutor behaviors and student achievement. It was demonstrated that the appropriate use of subject-matter expertise and social congruence were causally responsible for the emergence of cognitive congruence. Cognitive congruence, in turn, exerts a strong influence on group functioning and appeared to be related to both time spent by students on selfdirected learning and their achievement. This implies that these behaviors interact in fostering student learning. It may, therefore, well be that student 
tutors compensate for a relative lack in subject-matter expertise by an excess of social congruence, producing the same level of cognitive congruence found in staff tutors lacking an appropriate level of social congruence. This may be an explanation for the null-hypothesis outcomes in many of the student versus staff tutor studies.

The findings presented here also seem to have implications for the selection and preparation of tutors in problem-based learning. With respect to selection, the school only should employ tutors in units in which they have an adequate level of content expertise. With respect to the preparation of tutors, more attention should be given to cognitive and social congruence. Training should preferably take place 'on the job', with preparatory meetings in which tutors should be allowed to work with the actual problems to be presented to the students. While working on the job, tutors should regularly communicate to each other how they succeed, or fail, in helping students to overcome cognitive obstacles. In this way, tutors can acquire a broader range of possible interventions which might effectively stimulate students' cognition and motivation.

\section{References}

Barrows, H. S. (1988). The Tutorial Process. Springfield, ILL: Southem Illinois University School of Medicine.

Bender, W. (1983). Studenten de mond gesnoerd door autoriteit? (Student shut up by teachers' authority). Bulletin Medisch Onderwijs 2: 8-9.

Bentler, P. M. (1985). EQS. Structural Equations Manual. L.A., Cal., BMDP Statistical software, 3 print.

Cate, Th. J. ten (1986). Leren in Groepen Zonder Docent (Learning in groups without a teacher). PhD thesis, University of Amsterdam.

Collier, K. G. (1983). Syndicate methods placed in context, in K. G. Collier, ed, The Management of Peer Group Learning. Syndicate Methods in Higher Education (pp. 3-13). Guilford: Society for Research into Higher Education.

Collier, K. G. (1985). Teaching methods in higher education: The changing scene, with special reference to small group work. Higher Education Research and Development 4: 3-27.

Cornwall, M. G. (1980). Students as Teachers: Peer Teaching in Higher Education. Amsterdam: Centrum Onderzoek Wetenschappelijk Onderwijs.

Cronbach, L. J., Gleser, G. C., Nanda, H. \& Rajaratnam, N. (1972). The Dependability of Behavioral Measurements: Theory of Generalizability of Scores and Profiles. New York: John Wiley.

Grave, W. S. de, Volder, M. L. de, Gijselaers, W. H. \& Damoiseaux, V. (1990). Peer teaching and problem-based learning: Tutor characteristics, tutor functioning, group functioning and student-achievement, in Z. N. Nooman, H. G. Schmidt \& E. S. Ezzat, eds, Innovation in Medical Education. An Evaluation of its Present Status (pp. 123-135). New York: Springer Publ. Co.

Gruppen, L. D., Traber, P., Paine, M. E., Woolliscroft, J. O. \& Davis, W. K. (1992). Tutor-led and Student-led Small Groups: No Differences in Learning? Paper presented at the Annual Meeting of the American Educational Research Association, San Francisco, CA. 
Moust, J. H. C. (1993). De Rol van Tutoren in Probleemgesturrd Onderwijs. Contrasten tussen student- en Docenttutoren (On the role of tutor in problem-based learning: Contrasting student-guided with staff-guided tutorials). PhD-thesis, University Press, Maastricht, The Netherlands.

Moust, J. H. C., Volder, M. L. de \& Nuy, H. J. P. (1989). Peer teaching and higher level cognitive learning outcomes in problem-based learning. Higher Education 18: 737-742.

Powell, J. P. (1974). Small group teaching methods in higher education. Educational Research 16: $163-171$.

Sarbin, T. R. (1976). Cross-age tutoring and social identity, in V. L. Allen, ed, Children as Teachers (pp. 27-40). New York: Academic Press.

Schmidt, H. G. (1983). Problem-based learning: Rationale and description. Medical Education 17: $11-16$.

Schmidt, H. G. (1994). Resolving inconsistencies in tutor expertise research: Lack of structure causes students to seek tutor guidance. Academic Medicine 69: 656-662.

Schmidt, H. G., Van der Arend, A., Kokx I. \& Boon, L. (1993a). Peer versus Staff Tutoring in Problem-based Learning. Paper presented at the Annual Meeting of the American Educational Research Association, Atlanta, GA.

Schmdit, H. G., Van der Arend, A., Moust, J. H. C. Kokx I. \& Boon, L. (1993b). Influence of tutors' subject-matter expertise on student effort and achievement in problem-based learning. Academic Medicine 68(10): 784-791.

Volder, M. L. de, Grave, W. S. de \& Gijselaers, W. H. (1985). Peer teaching: Academic achievement of teacher-led versus student-led discussion groups. Higher Education 14: 643-650.

Webb, G. (1983). The tutorial method. Learning strategies and student participation in tutorials: Some problems and suggested solutions. Programmed Learning and Educational Technology 20: 117-121.

Webb, N. M. (1989). Peer interaction and leaming in small groups. International Journal of Educational Research 13: 21-41. 